\title{
Boundary Layer Clouds and Convection over Subtropical Oceans in our Current and in a Warmer Climate
}

\author{
Louise Nuijens $^{1} \cdot$ A. Pier Siebesma ${ }^{1,2}$
}

Published online: 4 May 2019

(C) The Author(s) 2019

\begin{abstract}
Purpose of Review We review our understanding of mechanisms underlying the response of (sub)tropical clouds to global warming, highlight mechanisms that challenge our understanding, and discuss simulation strategies that tackle them.

Recent Findings Turbulence-resolving models and emergent constraints provide probable evidence, supported by theoretical understanding, that the cooling cloud radiative effect (CRE) of low clouds weakens with warming: a positive low-cloud feedback. Nevertheless, an uncertainty in the feedback remains. Climate models may not adequately represent changing SST and circulation patterns, which determine future cloud-controlling factors and how these couple to clouds. Furthermore, we do not understand what mesoscale organization implies for the CRE, and how moisture-radiation interactions, horizontal advection, and the profile of wind regulate low cloud, in our current and in our warmer climate.

Summary Clouds in nature are more complex than the idealized cloud types that have informed our understanding of the cloud feedback. Remaining major uncertainties are the coupling of clouds to large-scale circulations and to the ocean, and mesoscale aggregation of clouds.
\end{abstract}

Keywords Low-cloud feedback · Emergent constraints · Turbulence-resolving models · Cloud-circulation coupling · Atmosphere-ocean coupling $\cdot$ Mesoscale aggregation $\cdot$ Moisture-radiation interactions

\section{Introduction}

Boundary layer clouds are influenced by many processes. This makes understanding their behavior challenging and predicting their behavior with a global climate model (GCM) ambitious, especially as many of those processes are unresolved in GCMs. Not only are boundary layer clouds relatively small (shallow cumulus) or thin (stratocumulus), they are driven by turbulent circulations that cover a range of scales. On the smallest scales, aerosols and turbulence determine the cloud microphysical structure, which influences how clouds modify radiative fluxes and their capability to

This article is part of the Topical Collection on Convection and Climate

Louise Nuijens

louise.nuijens@tudelft.nl

1 Delft University of Technology, Stevinweg 1, 2628 CN Delft, The Netherlands

2 Royal Netherlands Meteorological Institute (KNMI), De Bilt, The Netherlands produce rain. Small turbulent eddies and convective motions transport heat and moisture throughout the boundary layer, which trigger condensation and set cloud thickness and liquid water content. Those turbulent circulations are driven by surface temperature, large-scale wind, thermodynamic gradients, and radiative transfer, which in turn are influenced by the general circulation in the atmosphere and ocean.

An advantage for predicting clouds in GCMs is that certain clouds favor certain climatic regions on Earth. Stratocumulus favors the cold eastern oceans where large subsidence prevails, and shallow cumulus favors warmer SSTs where subsidence is weaker and winds are stronger. Such phenomenological relationships between the presence of clouds, relative humidity, and subsidence have been the basis for some of the first diagnostic formulations of clouds in global models, e.g., Slingo [1]. In current generation global models, these have made way for more intricate cloud schemes, which are coupled to turbulence, convection, and microphysics, which themselves are represented through empirical formulations. These parameterizations, and how they interact, underlie much of the uncertainty in the representation of boundary layer clouds in GCMs. 
These uncertainties have been revealed in predictions of global mean equilibrium surface temperature response to $\mathrm{CO}_{2}$ doubling, also called equilibrium climate sensitivity (ECS), which diverges considerably among GCMs. This spread largely depends on the predicted cloud changes in individual GCMs [2-4]. GCMs in which the cooling effect of clouds on climate strengthens with warming can dampen warming: a negative cloud feedback that leads to a lower climate sensitivity. Vice versa, GCMs in which the cooling effect of clouds weakens amplify the warming: a positive cloud feedback and a higher climate sensitivity. During the fifth assessment report (AR5) of the IPCC, the spread in GCM-predicted total cloud feedback ranged from 0.16 to + $0.94 \mathrm{~W} \mathrm{~m}^{-2}{ }^{\circ} \mathrm{C}^{-1}$ [5], and in the IPCC report itself was judged likely to be positive, with a probability range even larger (0.2 to $+2.0 \mathrm{~W} \mathrm{~m}^{-2}{ }^{\circ} \mathrm{C}^{-1}$ ), taking into account additional uncertainties such as feedback mechanisms missing from GCMs or CRM feedbacks outside of the GCM range [6]. The cloud feedback has been decomposed into three gross cloud properties-the cloud fraction, cloud optical depth, and cloud altitude-revealing that the spread in the cloud feedback comes primarily from the spread in the low-cloud amount feedback, ranging from -0.09 to $+0.63 \mathrm{~W} \mathrm{~m}^{-2}{ }^{\circ} \mathrm{C}^{-1}[5]$. This highlights that subgrid processes involving low clouds have far-reaching effects and may be crucial for understanding climate change.

The cloud feedback uncertainty has united two separate communities: the Global Atmospheric System Studies (GASS) panel (formerly the GEWEX Cloud System Study), which works on improving the understanding of cloud processes and their parameterization in climate and numerical weather prediction (NWP) models through field campaigns and turbulence or cloud-resolving models, and the Cloud Feedback Model Intercomparison Project (CFMIP), which works on improving the understanding and evaluation of clouds and cloud feedbacks in climate models. Together, these communities have developed methods to constrain uncertainties in cloud feedback. Turbulence-resolving models have been used to simulate the response of archetypal boundary layer cloud regimes to a composite large-scale forcing representative for our current and our future climate, also called forcing-feedback studies (note that we use forcing to refer to large-scale forcing, not radiative forcing). Furthermore, present-day observations have been used to find relationships between clouds and their large-scale environment, which have predictive skill, and may constrain modeled cloud feedbacks and ECS. Together, these approaches suggest a positive low cloud feedback. Excellent review papers summarize the outcomes of forcing-feedback studies using turbulence-resolving models [7••], of emergent constraints of the low-cloud feedback from cloud-controlling factors [8] and of the representation of cloud feedbacks in GCMs [9].
At the time of AR5, positive feedback in most GCMs, but the deficient representation of low clouds in GCMs, diverse results from large-eddy simulations (LESs) and cloudresolving models (CRMs), a lack of reliable observational constraints, and the tentative nature of suggested mechanisms were reasons to report a low confidence in the sign of the lowcloud feedback contribution [6]. Today, an increasing number of studies using LES, CRM, or observational constraints have increased our confidence in a positive feedback. We also have a better understanding of the processes that cause the spread in GCM-predicted feedbacks, including that GCMs with positive feedbacks may produce that sign of the feedback due to different mechanisms than in LES [10, 11].

But as our understanding is increasing, so is our comprehension of the complexity of clouds. In recent years, focus has shifted from constraining cloud feedbacks to understanding the interaction between cloud-related processes - microphysics, turbulence, and convection - and their coupling to largescale circulations [12]. Field studies and satellite imagery emphasize how clouds have much greater variability than the archetypal clouds in turbulence-resolving modeling studies. We do not fully understand mesoscale variability in cloud fields, nor whether this plays a critical role for the cloud feedback. Not all factors that may control clouds have been considered in forcing-feedback studies or observed emergent constraints. Moreover, (low) cloud radiative effects have been shown to promote the aggregation of deep convection and trigger circulations. As GCMs do not correctly predict changing SST patterns, which are shown to be important for understanding the temporal evolution of feedbacks [13], GCMs may not adequately predict changes in large-scale forcing that serve as input for forcing-feedback studies and emergent constraints.

How boundary layer clouds change from our current to a warmer climate therefore remains subject to a number of important uncertainties. In this paper, we summarize the studies and previous reviews that have helped us understand the low cloud responses to warming, with an emphasis on small-scale processes and mechanisms. Thereafter, we will discuss insights from the last 3 years that may lead us to question these mechanisms, or raise new ones. In doing so, our focus is on subtropical and tropical low clouds, as these drive the largest spread in GCM cloud feedbacks [9]. Finally, we discuss challenges in using simulations of low clouds to constrain the lowcloud feedback.

\section{Constraining the Tropical Low-Cloud Feedback}

\section{The Large-Scale Forcing—Feedback Framework}

In this framework, models are used to derive the cloud radiative effect in a current climate (control) and in a warmer climate (perturbed climate). Different models have been used, 
including LES, CRMs, and mixed-layer models (MLMs), with most confidence stemming from the first. The largescale forcing, a combination of large-scale factors that are considered important regulators of clouds (so-called cloudcontrolling factors), has been constructed based on CMIP model output $[14,15,16 \cdot 17]$, or more loosely inspired by the latter $[18,19,20 \bullet$. For the stratocumulus regime, the mixed layer model confirms many of the findings of LES $[15,19,21]$.

The CGILS LES intercomparison project $[14,17]$ has been one of the most influential efforts, using an ensemble of LES codes. CGILS focuses on the well-studied Pacific cross section [22] from the north tropical to subtropical ocean, which covers three low cloud regimes: well-mixed stratocumulus over cold SSTs, decoupled stratocumulus over cool SSTs, and shallow cumulus over warm SSTs. For each of these three cloud regimes, the response to a perturbed climate forcing is simulated. A limitation of CGILS is therefore that it does not evaluate a change in the frequency of occurrence of each regime. Arguably, a better estimate of the cloud feedback is derived from Langragian simulations of the transition from stratocumulus to cumulus, which has been explored with a single LES [23•]. However, overall cloud feedback estimates do not differ greatly between the CGILS setup, the Lagrangian setup, or even more idealized studies, ranging between 0.3 and $2.3 \mathrm{~W} \mathrm{~m}^{-2} \mathrm{~K}^{-1}$.

Different phases of CGILS have used different forcing composites, which has illustrated the sensitivity of the cloud feedback to different controlling factors and has led to a better understanding of the most important mechanisms underlying the feedback. These include thermodynamic, dynamic, stability, and radiative mechanisms, first introduced in Bretherton et al. [15] and illustrated in Bretherton [7••].

The original CGILS setup includes a $2^{\circ}$ warmer SST, a moist-adiabatic increase of the free tropospheric temperature profile (without significant change in estimated inversion strength), a moistening of the free troposphere, to maintain a constant relative humidity $(\mathrm{RH})$, and a weaker subsidence rate from the predicted slow-down of the Hadley/Walker circulation, as found in the Northeast Pacific [14]. In the second phase of CGILS, instead of forcing changes that might be representative for specific regions, the forcing change represents an average over subtropical oceans derived from the CMIP3 multimodel mean $[15,16 \cdot]$. These changes include a doubling of $\mathrm{CO}_{2}$, a reduction in the subsidence rate, but half that of the original CGILS setup, and a reduced free tropospheric relative humidity, an increase in estimated inversion strength (EIS), and a reduction in wind speed.

For the stratocumulus regime, using the original forcing, all LES codes predict a thickening of stratocumulus by raising cloud top, leading to a negative cloud feedback. Applying the same forcing but without a reduction in subsidence, all LES codes predict a thinning of stratocumulus and a positive cloud feedback. Without the dynamical effect of reduced subsidence, the thinning is caused predominantly by a thermodynamic and radiative effect. The thermodynamic effect includes an increase in cloud base height as the cloud layer dries, which happens in response to a burst of cloudtop entrainment that results from the increase in SST, increased surface evaporation, and increased liquid flux into the cloud layer. Due to the strong inversion and the sensitivity of stratocumulus tops to small changes in humidity, the stratocumulus layer adjusts very quickly (within an hour) into a slightly drier and less cloudy structure, but without longlasting increases in entrainment or cloud top height. This has also been called the entrainment-liquid flux adjustment [23•]) and is also found in idealized forcing studies [24], using a mixed-layer model [19], and also applies to the shallow cumulus regime [18, 23•]. The radiative effect is responsible for a lowering of cloud tops, a thinning of cloud, and a positive feedback. This is caused by less cloud-top entrainment, which results from reduced cooling from increased long-wave downwelling radiation under a moister free troposphere. Without this radiative effect, and even without the subsidence reduction, the feedback in LES is negative.

Using the forcing of the second CGILS phase, stratocumulus thins in all LES codes, leading to a positive cloud feedback [16•]. Not only is the dynamical-induced thickening of the cloud less strong due to more realistic reductions in subsidence, the radiative effect is enhanced with a doubling of $\mathrm{CO}_{2}$. Perturbations in EIS (stability effect) and in wind speed play a smaller role. In an additional perturbation, only $\mathrm{CO}_{2}$ concentrations are quadrupled, which idealizes the fast adjustment of the boundary layer to $\mathrm{CO}_{2}$ radiative driving, before SSTs can respond. This leads to similar $0-15 \%$ reductions in shortwave cloud-radiative effects, suggesting that fast adjustments are not unimportant for cloud changes.

In all LES codes, the cloud feedback in the shallow cumulus regime is smaller than that of the stratocumulus regime, exemplifying the robustness of shallow cumuli to perturbations in their environment. Dynamic mechanisms play a minor role, as cumulus updrafts are much stronger than mean subsidence rates. Because cumulus cloud fractions are small, radiative cooling is mostly regulated by clear-sky radiative cooling. At warmer SSTs, larger downwelling longwave fluxes from a moister free troposphere imply less radiative cooling in the boundary layer, but this reduction in cooling is counteracted by larger cloud layer humidity $[16 \bullet, 25]$. Radiative mechanisms are therefore also small. Furthermore, changes in the depth of shallow cumuli are limited, because this regime produces precipitation readily, which helps buffer cloud deepening $[16 \cdot, 20 \cdot$. The only notable change in this regime is a slight reduction in cloud cover. This happens due to a similar thermodynamic effect as in the stratocumulus regimes ( [18]; Bretherton and Blossey 2013). After the instantaneous warming, increased surface evaporation and 
liquid fluxes create a burst of entrainment, causing a warming and a lowering of relative humidity throughout the boundary layer. The decrease in cloud cover is small, especially because cloud fraction near cloud base - the dominant contributor to cloud cover-is effectively constrained by dynamics involving the height of the transition layer with respect to the lifting condensation level [26, 27].

A more realistic coupling of clouds to the surface energy budget is also crucial, as exemplified by a few studies that have coupled a simple MLM framework [21] or LES [28, 29] to a slab ocean model with interactive SST, prescribing the ocean heat uptake instead. In their extension of the CGILS simulations, Tan et al. [29] show that the positive cloud feedback for the stratocumulus regime is much larger than in the original CGILS cases, because the breakup of the stratocumulus cloud deck triggers an abrupt and large SST increase and MBL deepening, which do not occur in fixed-SST experiments.

\section{Emergent Constraints from Observed Cloud-Controlling Factors}

A growing number of studies are providing observational support for the mechanisms underlying cloud changes in LES. Evidence for the thermodynamic mechanisms has been given by Qu et al. [30], who show that for fixed estimated inversion strength (EIS), positive SST anomalies are associated with negative cloud amount anomalies. Reduced subsidence has been found to favor thicker cloud [31], providing evidence for the dynamic mechanism. Much evidence exists for the stability (EIS) mechanism: a larger EIS correlates with larger cloud amount and thus favors a stronger SWCRE [32, 33, 34•]. Myers and Norris [34•] also show that increased free tropospheric humidity promotes cloud cover via reduced entrainment drying. But more humidity in the entire column above the stratocumulus deck also leads to less cloud-top radiative cooling, which can promote cloud thinning [19••]. Eastman and Wood [35] show that this radiative effect of additional free tropospheric humidity is three to four times more important than the entrainment effect, at least for the rate of increase of boundary layer height. Less cloud-top cooling and stratocumulus thinning have also been observed for stratocumulus layers with cirrus overhead [36]. But the relative importance of radiative and entrainment effects for current climate variability in low clouds is still unclear. Lastly, wind speed and cold air advection have been shown to promote cloud amount ( [37-39]) and are the best predictors of shallow cumulus cloud amount [40, 41•].

Such observed relationships between low cloud amount, shortwave cloud radiative effects, and cloud-controlling factors in our current climate may be used to predict how low clouds change in a warmer climate, based on GCM-predicted changes in those cloud-controlling factors. In this approach, clouds respond to the local values of the cloud-controlling factors, while cloud-controlling factors may depend on nonlocal factors such as the large-scale circulation, which can be expressed as a function of the global mean surface air temperature. A number of assumptions underlie this approach: the observed relationships are assumed to be constant across timescales longer than a few days (when the boundary layer has fully adjusted to any changes in cloud-controlling factors) and reflect the influence of cloud-controlling factors on clouds, and not vice versa [8].

Although some cloud-controlling factors may be important for cloud variability in our current climate, they might not be that important for climate change when their change with warming is small. For instance, GCM-predicted changes in subsidence or winds are much smaller than predicted changes in SST and EIS. This makes the thermodynamic and stability mechanisms that lead to positive feedbacks more important for climate. Klein et al. [8] combined five extensive observational studies using a range of datasets [42-46] to derive a local estimate of the cloud feedback, which is -1.0 to + $1.9 \mathrm{~W} \mathrm{~m}^{-2} \mathrm{~K}^{-1}$. As many of the individual estimates are concentrated in a narrower range, a consensus estimate was also derived and equal to $0.3-1.7 \mathrm{~W} \mathrm{~m}^{-2} \mathrm{~K}^{-1}$. Although Klein et al. [8] notes that the approach may be improved by including more observations from the trade-wind cumulus regions, this provides further support that the low-cloud feedback is not negative.

\section{Uncertainties in the Low-Cloud Feedback}

Combined, the forcing-feedback framework using LES and the emergent constraints from observations highlight the robustness of a positive cloud feedback, produced by a thinning of stratocumulus as climate warms, and a faster transition from stratocumulus to cumulus. At the same time, the scatter among LES codes is significant, due to different subgrid turbulence and advection schemes. Especially for the decoupled stratocumulus (transition) regime, LES codes can predict feedbacks of opposite sign in response to specific controlling factors. Even when absolute differences are small, this challenges our understanding of the mechanisms underlying the feedback. The assumption that GCMs correctly predict the change in cloudcontrolling factors with warming, which also underlies the emergent constraints approach, is therefore a critical assumption. Recent studies highlight the uncertainties in GCMpredicted tropical Pacific SST patterns and related tropospheric stability changes $[13,47 \bullet \bullet, 48 \bullet \bullet$. The possibility that SST patterns change with warming seems significant, and this appears to increase the relative importance of stability (EIS) and dynamical (subsidence) mechanisms in low cloud regions, which would favor a smaller positive or negative feedback. Climate-dependent changes in ocean heat uptake are also 
uncertain and important for the cloud feedback, as the studies using LES coupled to an ocean slab model suggest [29].

A further limitation to the feedback derived from LES may be the lack of mesoscale and large-scale variability in such simulations. The interaction of clouds with largerscale dynamics, such as the strength of Hadley and Walker cells, tropical transient wave activity, or midlatitude synoptic wave activity, is absent in setups such as CGILS. Figure 1 illustrates the variability in cloud structures observed across about $4300 \mathrm{~km}$ over the subtropical North Atlantic (topmost satellite image), zoomed in to an area of $550 \mathrm{~km}$ (middle left image). Also shown are the typical cloud fields produced with LES of shallow cumulus using domain sizes spanning 12.8 or $50 \mathrm{~km}$ in one dimension, which is larger than used in the CGILS exercise (2.4 $\mathrm{km}$ for the stratocumulus regime and $9.6 \mathrm{~km}$ for the shallow cumulus regime). Evidently, the size of aggregated cloud clusters in the satellite image, such as in the central North Atlantic, is on the order of $100 \mathrm{~km}$ or even larger, comparable or larger than LES. At $50 \times 50 \mathrm{~km}^{2}$, the LES starts to produce the smaller cold pool structures $(O$ $10 \mathrm{~km}$ ), such as indicated in the outset of the satellite image. Larger cold pool structures on the order of $100 \mathrm{~km}$ are also seen. How the cloud feedback depends on domain size spanning from $10 \mathrm{~km}$ (as used in CGILS) to a few hundreds of kilometers has not yet been evaluated.

With respect to realistic variability, the observed emergent constraints approach has added value, because the coupling of clouds to a varying large-scale state and the presence of mesoscale cloud organization are implicit in observed relationships. But in that approach, it is also assumed that such relationships do not change as climate warms and that cloud-controlling factors meaningfully predict cloud organization. However, the relative role of the observed controlling factors in regulating mesoscale cloud organization is unclear. Recent work suggests that factors such as SST, surface wind speed, and wind shear indeed correlate with specific cloud patterns in the trade-wind cumulus regions (personal communication, Bony). In particular, the role of wind shear is poorly understood. At the same time, the importance of cloud, water vapor, and radiation interactions in the self-aggregation of convection, the subject of many recent studies, implies less dependence on large-scale controlling factors.

In the remainder of the paper, we discuss recent work in what we believe are three important areas that lack understanding: the coupling of clouds and convection to the ocean, the coupling of clouds to circulations, including moisture-radiation interactions and the interaction with horizontal wind, and mesoscale organization or aggregation. In doing so, we will also review recent developments in turbulence and cloud-resolving simulations that may help reduce uncertainties.

\section{Atmosphere-Ocean Coupling}

The uncertainties in changing SST patterns with global warming $[13,47 \bullet \bullet, 48 \bullet \cdot]$ are raising awareness about the role of atmosphere-ocean coupling mechanisms in the (low) cloud feedback problem. Spatial patterns in SST, as set by ocean dynamics, have been shown to play an important role in setting patterns of winds, clouds, and rain, and an open question is to what extent they also regulate mesoscale SST patterns and the organization of clouds, through mesoscale ocean eddies $[49,50]$. Vice versa, clouds and convection are crucial for the surface energy budget.

Bellomo et al. [51, 52] demonstrated the impact of clouds on the net radiative heating at the surface and on SST variability in an atmospheric GCM coupled to a slab ocean. Furthermore, the LES studies using an ocean mixed layer showed that the cloud feedback in stratocumulus regions is significantly different when clouds influence the surface energy budget $[28,29]$. In those studies, a major uncertainty remains how ocean heat uptake changes with global warming.

A coupling of the atmosphere to the ocean is not only established through cloud-radiative effects, but also through convective mixing. By mixing drier free tropospheric air into the boundary layer, shallow convection promotes surface evaporation, which makes the depth of clouds and the boundary layer important factors to consider in the surface energy budget [53]. Surface fluxes and SSTs are also regulated by near-surface winds $[53,54]$, which hints at momentum transport being potentially important. In the inner tropics, where the Coriolis force becomes small, convective momentum transport (CMT) plays an important role at setting patterns of surface winds and explaining modeled biases in surface winds $[55,56]$. An open question is whether shallow convective momentum transport also has a meaningful influence on large-scale circulations.

\section{Cloud-Circulation Coupling}

\section{Interaction with Deep Convection and Large-Scale Circulations}

A number of studies have emphasized the importance of circulations between regions of deep convection and low clouds for the behavior of deep convection and its dependence on SST, and thus for global circulations and climate more generally. Using cloud-resolving models, several studies show that the large radiative cooling of a moist boundary layer underneath a dry free troposphere, further enhanced by low-level clouds, triggers mesoscale circulations that transport moist static energy into areas of deep convection, leading to aggregation of deep convection [57-59]. As deep convection aggregates, the free 

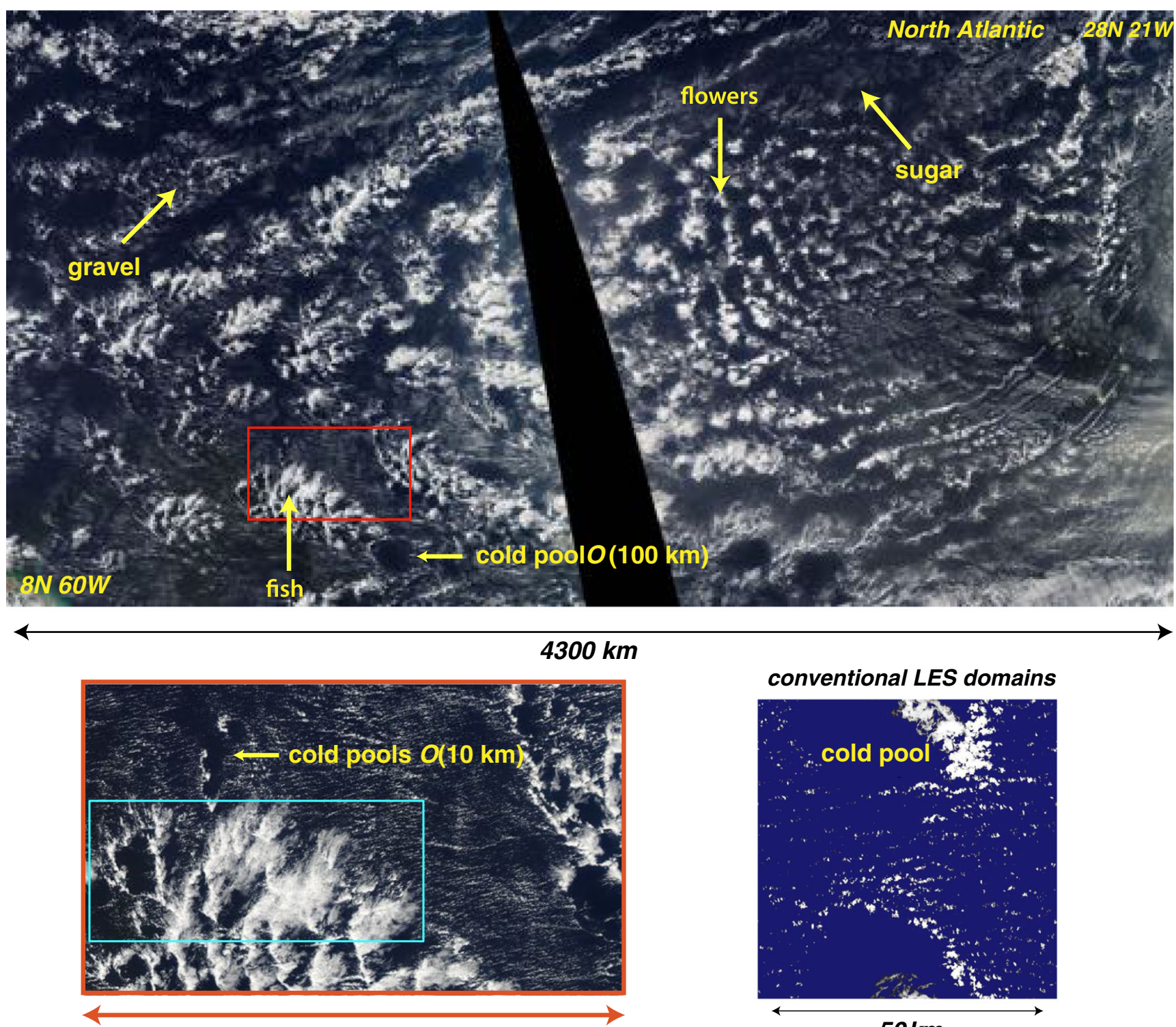

$550 \mathrm{~km}$

conventional LES domains

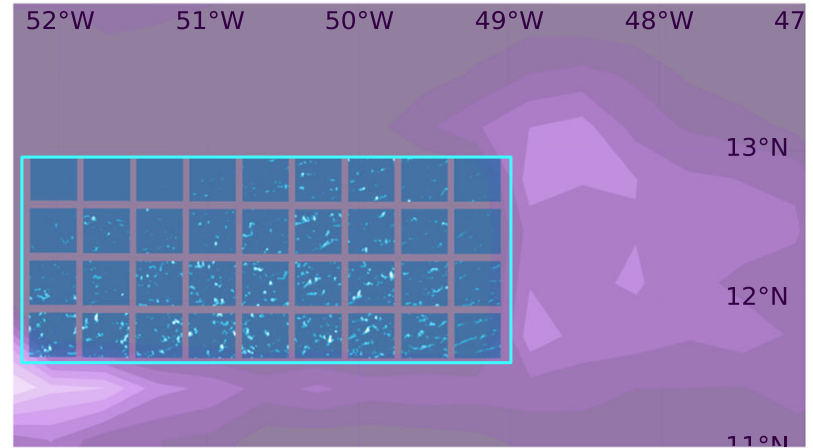

coupled DALES domains $\left(12.8 \times 12.8 \mathrm{~km}^{2}\right)$ in the IFS

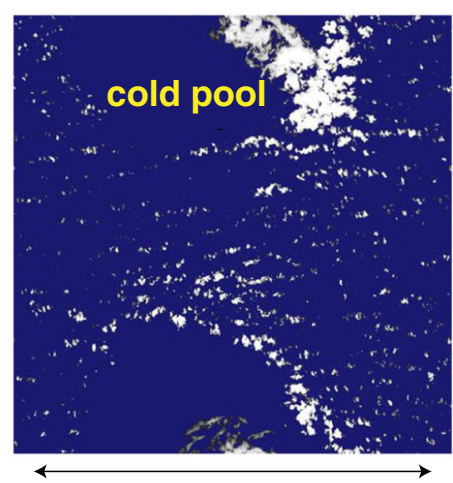

$50 \mathrm{~km}$

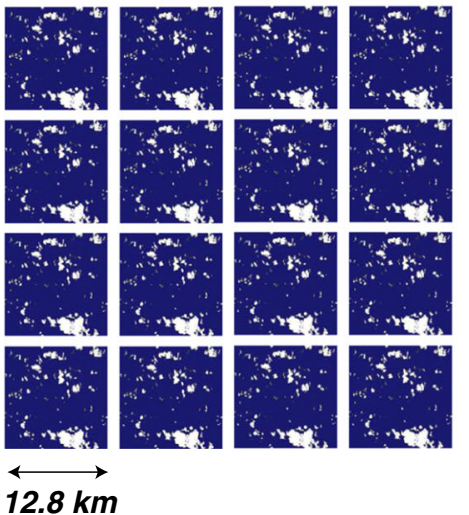

Fig. 1 Shallow convection over the Northern Atlantic ocean as viewed by MODIS Aqua at 13:30 local time on December 12, 2013 (top); zoom in on a subarea (middle, left), which is simulated by a superparameterized version of the ECMWF-IFS (T152), using several coupled Dutch atmospheric LES domains, each $12.8 \times 12.8 \times 5 \mathrm{~km}^{3}$, with a 200 -m horizontal grid spacing (bottom, left); conventional idealized LES simulations using domains of $50 \mathrm{~km}$ and $12.8 \mathrm{~km}$ in both dimensions (middle and bottom right, respectively), here for the case simulated in Vogel et al. [20] 
troposphere in the surrounding area becomes drier, which leads to a greater emission of longwave radiation to space, and may thus have important implications for climate sensitivity [60].

Conceptual models of the tropical atmosphere have also demonstrated an important influence of radiative cooling of low cloud regimes on large-scale overturning Hadley/ Walker circulations, by narrowing the area of deep convection $[61,62]$ or controlling subsidence rates $[63,64]$. Importantly, the radiative cooling from the humidity gradient across the inversion, on which shallow convection has an important influence, drives a shallow overturning circulation that is comparable with that introduced by SST gradients [65.], and might play a role in the presence of shallow overturning circulations in the tropical atmosphere [66]. This challenges a long-established class of theory, on which the work by Lindzen and Nigam [67] has had a large influence, in which low-level winds are solely driven by SST gradients, and which neglects pressure gradients at the top of the boundary layer that result from diabatic or radiative heating in the free troposphere [55,68].

When shallow cumuli have tops beyond $2 \mathrm{~km}$, the net latent heating due to precipitation becomes an important term in the heat budget of the lower atmosphere [20 , 63], and satellite observations suggest that diabatic heating cannot be ignored when thinking of what sets the strength of large-scale circulations. CloudSat data show that convective warm rain contributes $50 \%$ of column latent heating, even though its occurrence frequency is only $11 \%$ [69]. Satellite observations also show that when shallow overturning circulations in the tropical Eastern Pacific are strong, this region of the Pacific is characterized by large clusters of warm rain. Weaker shallow circulations are accompanied with a larger fraction of smaller isolated raining cells [70].

Overall, these studies suggest that changes in low clouds, and accompanying changes in the diabatic heating profiles of regions with low clouds, will change the properties of regions with deep convection and the circulation that connects them. An open question is whether GCMs represent such a coupling adequately and what this implies for their predicted low-cloud feedback and the change in cloud-controlling factors that is used as input for the forcing-feedback and emergent constraint frameworks.

\section{Moisture-Radiation Interactions}

Humidity is closely coupled to the clouds themselves, and therefore, only free tropospheric humidity is considered an external cloud-controlling factor. The influence of free tropospheric humidity on macroscopic properties of low clouds has long been recognized, via its influence on buoyancy gradients at the inversion and mixing and entrainment at cloud tops.
Studies of the low-cloud feedback have also highlighted the importance of free tropospheric humidity via radiative effects $[16 \bullet, 25,71]$, which has motivated recent idealized studies on the role of moisture-radiation interactions in setting the behavior and organization of shallow cumulus fields already in our current climate.

Shallow cumulus tops and precipitation appear especially sensitive to small changes in free tropospheric humidity, whereby a drier free troposphere promotes deeper cumuli and more precipitation than a moist free troposphere. The entrainment of drier air into the boundary layer not only enhances surface fluxes, a moist boundary layer underneath a drier free troposphere also experiences larger radiative cooling. In layers with small cloud fractions, in which clearsky radiative cooling dominates, this leads to a destabilization of the cloud layer, greater updraft buoyancy, and deeper cumulus clouds $[20 \bullet, 72,73]$. Once shallow cumulus clouds develop tops beyond $2 \mathrm{~km}$ and organize into larger clusters, the humidity profile within the boundary layer changes markedly, with much drier cloud layers, less cloud amount, and weaker moisture gradients across the inversion [20•]. In some way, these responses resemble the drying of the environment that accompanies the aggregation of deep convection.

Variations in free tropospheric humidity may thus play a role in regulating the depth of shallow cumulus clouds and the precipitation that they produce, as well as the aggregation into larger clusters that approach cumulus congestus (see also the next section on mesoscale organization). Such variability in humidity may be set on larger scales, such as dry air intrusions from mid-latitudes or moist and dry layers set by nearby deep convection [63,74], but the importance of the moisture profile above the boundary layer for radiative effects within the boundary layer remains unclear and requires further study. Recent work assesses the ability of space-borne observing systems at mapping water vapor profiles and discusses new technologies that may provide better observations of lower tropospheric water vapor that can help unravel moistureradiation interactions [75-77].

\section{Interactions with Horizontal Wind and Wind Shear}

Within the trade-wind cumulus regime, observed correlations with cloud-controlling factors are generally poor, but a relationship between low cloud cover and the near-surface wind is apparent $[40,41 \bullet]$. This relationship likely reflects the correlation between wind speed and wind direction [40] and the importance of air mass history, as well as the deepening response of shallow cumulus to increased surface evaporation under stronger winds [78]. However, it may also reflect the influence of wind speed changing with height throughout the lower troposphere (from the surface up to $\sim 4 \mathrm{~km}$ ): low-level wind shear. The profile of wind speed is a poorly observed quantity over ocean and not included as a cloud-controlling 
factor in cloud-feedback studies. Low-level wind shear obviously increases cloud cover, an effect that can be, but is not typically, included in cloud overlap assumptions in climate models [79]. Wind shear also influences cold pool dynamics and convective development by regulating where precipitation falls and evaporates [80]. Furthermore, ongoing work using idealized LES shows that wind shear limits the depth of shallow cumuli and thus the trade-wind inversion, and wind shear is effective at regulating the otherwise robust cloud base cloud amount (Helfer et al. personal comm.).

Effects of wind shear on entrainment and mixing are better understood for stratocumulus, through the use of LES [81] and more recently direct numerical simulations (DNSs) [82॰]. Mixing at stratocumulus tops can be enhanced by shear instabilities that are intrinsic to stably stratified shear layers, and which quickly thicken the cloud top region. Shear can also interact with convective instabilities driven by radiative and evaporative cooling. Recent DNS provide observable constraints on the importance of such effects [83], which should be evaluated against other cloud-controlling factors.

\section{Mesoscale Organization}

Satellite imagery such as in Fig. 1 illustrates the complexity of the cloud structures that can be found over subtropical oceans, here the Atlantic Ocean. Traditionally, this region is considered to be home of unorganized shallow cumulus convection and is often parameterized in this way in GCMs. But in reality, it is populated with a wide range of cloud structures, ranging from small isolated shallow cumuli of $\mathrm{O}(1-10 \mathrm{~km})$, to shallow cumuli organized in larger cold pool structures of $\mathrm{O}(10$ $100 \mathrm{~km})$ and even into larger organized cumuli of $\mathrm{O}(50$ $500 \mathrm{~km}$ ) that are accompanied by extended stratiform cloud layers near their tops. The cloud structures take a variety of shapes and structures, becoming horizontally heterogeneous, thickening in some places or thinning in others, and becoming cloudier downstream. The different structures that cloud fields adopt, which no longer are statistically homogeneous in the horizontal, are often broadly denoted as mesoscale organization, which may include closed or open cells in stratocumulus, cold pool structures in shallow cumulus fields, and more irregularly distributed aggregated deeper cumulus clusters.

Although mesoscale organization in low clouds has been appreciated since the 1950s [84], interest in this subject has picked up in light of recent studies on the aggregation of deep convection and its dependence on SST $[58,85,86]$. An important question with respect to the low-cloud feedback is whether boundary layer cloud fields that are organized differently exert different radiative effects and whether mesoscale organization will change as climate warms.

An objective classification of mesoscale organization from satellite imagery would aid a more systematic investigation of such questions, but measures of organization are challenging to define and more readily explored for deep convection [87, 88]. A recent effort hosted by the International Space Science Institute has focused on the (subjective) identification of different structures of trade-wind cumulus fields in 10 years of satellite imagery and led to the classification of four recurring patterns: sugar (fields of small popcorn cumuli), gravel (random fields of larger cumuli with cold pools), fish (clustered cold pool regions) and flowers (regularly distributed larger cumuli with tops near 2-4 km, accompanied by extended stratiform layers near cumulus tops and cloud-free areas in between). Some examples of these are indicated in the satellite image in Fig. 1.

Such extended stratiform layers of cloud that accompany flowers or fish are observed as far downstream of the transition as Barbados, and may be important for the cloud feedback, because they make up a third of total cloud cover and contribute most to monthly and seasonal variability in cloud cover, at least near Barbados [27]. Recent field campaigns in the Pacific also report the frequent occurrence of thin inversion layer cloud in the transition from stratocumulus and cumulus, where they commonly occur along with aggregated cumulus patches of $10 \mathrm{~km}$ wide, and likely constitute the majority of the cloud cover within these patches [89॰]. In that region, the ultraclean layers (UCLs) or veil layers are found to have very low cloud droplet concentrations, for which precipitation scavenging appears key [90]. Even when the layers are thin, they can still introduce important longwave radiative effects through their temperature difference with the underlying surface. Their significance for the radiation budget remains to be evaluated using observations, but it is clear that such stratiform layers will be a major challenge for GCMs with their limited vertical resolution [91]. Even in LES, different numerical schemes and a lack of vertical resolution result in a large spread in stratiform cloud amount at the inversion $[92,93]$.

As mentioned earlier, important questions are how the mesoscale patterns are caused by processes that take place on cloud or mesoscales or whether they are influenced by changes in the large-scale state. A number of studies have shown that for LES domains of at least $50 \times 50 \mathrm{~km}^{2}$, gravel or cold pool structures will arise [94-96] and larger clusters can develop with stratiform cloud near their tops [20•], although those clusters are notably smaller than in nature, and much shorter-lived. Shallow convection appears to spontaneously aggregate into such clusters, even when precipitation or mesoscale radiative and surface flux feedbacks are suppressed and cold pools are absent [97•]. At the same time, first analyses that correlate the subjective cloud classification with reanalysis data suggest that large-scale cloud-controlling factors, including SST, surface winds, zonal wind shear, EIS, and free tropospheric humidity, favor specific mesoscale patterns. If true, this implies that the type of mesoscale organization we find in a warmer climate may be different, which is relevant for the cloud feedback. 
In the following section, we will elaborate more on the advances and challenges in simulating boundary layer clouds, and thus whether these can help to further constrain the cloud feedback.

\section{Constraining the Low Cloud Feedback with Simulations}

As earlier mentioned, the conventional LES studies that have informed our understanding of the low-cloud feedback have two important limitations, namely, that they miss the variability in large-scale dynamics present in real atmospheres and are generally performed on domain sizes that are comparable with the scales of organization seen in nature. Furthermore, different numerical schemes, microphysics, and a lack of vertical resolution still result in a large spread in simulated cloud amount among LES codes [92, 93, 98]. LES therefore offers little constraint on the relationships between mesoscale organization, cloud cover, and radiative effects, which differ even in one LES when using different microphysical schemes [95].

A number of different approaches have been undertaken or are underway that may solve some of these issues. One approach is the use of large-domain LES or near-global cloud-resolving models (CRMs) to estimate the cloud feedback. For instance, the SAM CRM has been run in a near-global aquaplanet mode with a horizontal resolution of $4 \mathrm{~km}$ [99]. Despite this limited grid resolution, which does not resolve shallow cumulus clouds, these runs provide an interesting link to the generally smaller feedback found in global models. Under a $4 \mathrm{~K} \mathrm{SST}$ increase, this CRM namely predicts an increase in subtropical cloud amount and thus a negative cloud feedback, which correlates with modest increases in EIS and stronger boundary layer radiative cooling, which is hypothesized to trigger more convective moistening and enhanced cloudiness [25]. The negative feedback is reproduced in limited-area SAM using advective forcing derived from the driest column relative humidity quartile of the $+4 \mathrm{~K}$ aquaplanet runs (personal communication, Narenpitak).

An alternative approach to using large-domain LES is to embed a CRM as a local model in the grid columns of GCMs or NWP models, thus replacing conventional and uncertain convection and cloud parameterizations [100], yet maintaining the coupling to the circulation. This superparameterization (SP) approach, first proposed by Grabowski and Smolarkiewicz [101], is typically done using two-dimensional CRMs with a horizontal resolution of 1-4 km and has been explored in early work on cloud feedbacks using the SP version of the Community Atmosphere model (SP-CAM) [25, 71]. However, analyses of GCMs that use a superparameterization suggest that the variability of moisture in the local model is underestimated
[102]. This bias is likely attributable to the coupling between the resolved variability in the global model and the variability in the local model, because only tendencies of the mean fields are communicated between the local and the global model. Furthermore, at least most often implemented in SP-CAM, surface fluxes do not vary across the CRM domain, and radiation is computed at the GCM time step, so that surface flux feedbacks and radiationconvection feedbacks that might be important for convective aggregation are absent or not as strong.

To superparameterize boundary layer turbulence and low clouds, higher resolution LES models are needed as a local model (Grabowski 2017). Two approaches for this ultraparameterization approach are being pursued to cope with the computational limitations. One approach $[103,104]$ compromises the horizontal domain size of the local model to be limited to $\mathrm{O}(1 \mathrm{~km})$. Another approach is to apply the ultraparameterization approach only regionally in the global model, but using the resolution of the global model as the domain size of the local model [105]. Although this latter approach can be considered as a benchmark of parameterizations for cloud-related processes, it still does introduce a scale break at the grid resolution scale of the global model, which prevents the formation of cloud structures with a horizontal extent beyond the domain size of the local model. For instance, recent simulations embedding the Dutch Atmospheric LES (DALES) model in the IFS model, each with a domain size of $12.8 \times 12.8 \mathrm{~km}^{2}$, reveal that the different SP grids all have very similar cloud fields, lacking organization at scales larger than the global model grid, even when the DALES domains are coupled. Figure 1 shows the coupled DALES results for the specific day and time at which the satellite image was taken (bottom row) for the blue outset of the already zoomed in red outset of the original image. In yet another approach, observations or LES are used for (machine) learning approaches $[106,107]$. This is not without challenges either, for instance, datasets need to capture a wide-enough varying atmosphere to prevent algorithms from making inaccurate predictions when confronted with situations for which they were not trained.

How the small-scale resolved flow couples with the largescale flow is an area of active research, and relatively few studies have explored the issues that might emerge, even before high-resolution simulations can be used to study the cloud feedback. The ability of LES to predict realistic cloud structures once forced with realistic and varying large-scale states also requires validation from observations. This is most effective using LES driven by weather hindcasts centered at locations where in situ measurements are readily available. A number of recent studies and programs have demonstrated this capability. Observations collected along the Pacific stratocumulus-to-cumulus transition during ship cruises (MAGIC campaign) demonstrate skill of 
Lagrangian LES runs in simulating the timing of the transition and associated cloud and boundary layer properties [108]. A proof-of-concept study demonstrated that explicit simulation of turbulence is stable enough to simulate an entire year of conditions that vary from stable boundary layer to deep convective events [109]. Such LES runscentered at the Cabauw observational supersite in the Netherlands-will become operational in 20(20) as part of the Dutch Ruisdael Observatory. Since 2015, the DOE ARM program is taking a similar approach with its LES ARM Symbiotic Simulation and Observation (LASSO) program at the US continental supersite Southern Great Plains. The HD (CP)2 (High-Definition Clouds and Precipitation for advancing Climate Prediction) Observational Prototype Experiment (HOPE) conducted in Germany was used to validate multi-week simulations with the ICON-LES model on a day-to-day basis [110]. They demonstrated that while LES models capture boundary layer characteristics reasonably well, they struggle with reproducing correct cloud statistics, which depends on how the forcing data is constructed and how much (mesoscale) variance it contains [110]. This again emphasizes that not just small scales, but also large scales introduce important variance that sets cloud characteristics.

Even as (near-)global high-resolution simulations at the kilometer scale become more feasible, and new simulation approaches are advancing, in situ measurements and global satellite data remain invaluable. Global convectionresolving simulations also illustrate that uncertainties will shift from convection to microphysics [104, 111]. This once more emphasizes that one of our challenges is to investigate the relative influence of small-scale versus large-scale processes at setting cloud behavior. Groundbased remote sensing and in situ aircraft measurements of turbulence and cloud/rain microphysics remain necessary to help constrain these effects. These will be especially useful when combined with measurements and simulations that constrain the influence of the large-scale forcing, such as planned for EUREC4A [112]. Additionally, models that no longer rely on the parameterization of turbulence at all, e.g., DNS, should be used as a reference alongside LES to test how sensitive entrainment velocities are to changes in forcing or to study the importance of getting the correct droplet size distributions near stratocumulus tops [113].

\section{Conclusions}

We reviewed two approaches used to estimate the low-cloud feedback and highlighted recent studies that shed light on mechanisms controlling cloud behavior that are potentially important for the feedback. Supported by theoretical understanding, the large-scale forcing-feedback framework using turbulence-resolving simulations and the emergent constraints from observations suggest that the feedback involving classical boundary layer cloud regimes is positive. However, the spread of cloud feedback estimates among turbulenceresolving models and observational studies highlights caveats, which underlie uncertainties in our understanding of cloudcontrolling mechanisms in our current and in a warmer climate.

- Clouds respond to many controlling factors in opposing ways that could imply positive or negative feedbacks. This makes knowing the precise nature of changes in controlling factors crucial.

- The precise nature of changes in controlling factors derived from climate models is subject to uncertainty. Major uncertainties are the change in SST patterns during global warming, and how clouds affect and respond to the surface energy budget and large-scale circulations.

- Unclear is whether all important cloud-controlling factors are considered. A few factors typically not considered, but which appear to play important roles at least in controlling cloud variability in our current climate, are the vertical structure of water vapor and its interaction with radiation, large-scale horizontal moisture and temperature advection, and the vertical structure of wind.

- Provided we know the precise nature of the forcing perturbation, self-aggregation mechanisms in cloud fields may be very important in controlling clouds and their radiative effects. The relative importance of selfaggregation mechanisms versus large-scale factors in controlling clouds, and how this might change with warming, is not well understood.

- Turbulence-resolving models diverge in their responses to cloud-controlling factors due to differences in subgrid turbulence and microphysics parameterizations, their numerical schemes, and whether they are coupled to an interactive ocean model and interact with the large-scale circulation. Models generally underestimate cloudiness in broken cumulus fields and stratiform layers near cumulus tops, and they lack the mesoscale and large-scale variance in observed cloud fields. Neither LES nor satellite studies have sufficiently evaluated cloud regimes with organized and larger shallow cumuli with tops near 2-4 km.

We thus require better understanding of mechanisms that involve the variability of boundary layer cloud fields in nature, their self-organizing mechanisms, and the interaction of clouds with circulations and the oceans, including via winds. Unraveling these mechanisms has been a recent focus of the cloud-climate community, which has launched a number of measurement and simulation efforts where clouds are studied in realistic settings. In the next years, we expect significant progress in understanding cloud behavior from turbulence- 
resolving models that are run at large domains, even approaching global scales. When these accompany intensive measurement periods or field campaigns, they can be directly evaluated using observations. Similar model setups can be subjected to future climate forcing scenarios following the forcing-feedback studies described herein. Additionally, we expect progress in using LES-based superparameterized global models to understand cloud changes, as they provide realistic large-scale dynamics along with turbulence-resolving embedded simulations in a two-way coupled framework. A new challenge will be to analyze the enormous amounts of data in useful ways, and we encourage that this goes hand-inhand with conceptual studies to isolate and understand individual mechanisms.

Open Access This article is distributed under the terms of the Creative Commons Attribution 4.0 International License (http:// creativecommons.org/licenses/by/4.0/), which permits unrestricted use, distribution, and reproduction in any medium, provided you give appropriate credit to the original author(s) and the source, provide a link to the Creative Commons license, and indicate if changes were made.

\section{References}

Papers of particular interest, published recently, have been highlighted as:

- Of importance

•. Of major importance

1. Slingo JM. The development and verification of a cloud prediction scheme for the ECMWF model. Q J R Meteorol Soc. 1987;113: 899-927.

2. Cess RD, Potter GL, Blanchet JP, Boer GJ, Del Genio AD, Deque $\mathrm{M}$, et al. Intercomparison and interpretation of climate feedback processes in 19 atmospheric general circulation models. J Geophys Res. 1990;95:16601-15. https://doi.org/10.1029/ JD095iD10p16601.

3. Vial J, Dufresne J-L, Bony S. On the interpretation of inter-model spread in CMIP5 climate sensitivity estimates. Clim Dyn. 2013;41(11-12):3339-62.

4. Bony S, Dufresne J-L. Marine boundary layer clouds at the heart of tropical cloud feedback uncertainties in climate models. Geophys Res Lett. 2005;32:L20806. https://doi.org/10.1029/ 2005GL023851.

5. Zelinka MD, Klein SA, Hartmann DL. Computing and partitioning cloud feedbacks using cloud property histograms. Part I: cloud radiative kernels. J Clim. 2012;25(11):3715-35. https://doi.org/10.1175/JCLI-D-11-00248.1.

6. Boucher, O., Randall, D., Artaxo, P., Bretherton, C., Feingold, G., Forster, P., ... Zhang, X. Y. Clouds and Aerosols. In: Climate Change 2013: The physical science basis. Contribution of Working Group I to the Fifth Assessment Report of the Intergovernmental Panel on Climate Change, Cambridge: Cambridge University Press; 2013:571-657. Doi:https://doi.org/ 10.1017/CBO9781107415324.016.

7.• Bretherton CS. Insights into low-latitude cloud feedbacks from high-resolution models. Phil. Trans. Roy. Soc. A. 2015;373:
20140415. https://doi.org/10.1098/rsta.2014.0415. This is a very complete review of high-resolution modeling studies of the low cloud feedback with supporting physical understanding.

8.• Klein SA, Hall A, Norris JR, Pincus R. Low-cloud feedbacks from cloud-controlling factors: a review. Surv Geophys. 2017;38:130729. https://doi.org/10.1007/s10712-017-9433-3. This review summarizes the evidence for the low cloud feedback and its controlling mechanisms from observations.

9.• Ceppi P, Brient F, Zelinka MD, Hartmann DL. Cloud feedback mechanisms and their representation in global climate models. WIREs Climate Change. 2017;8:e465. https://doi.org/10.1002/ wcc.465. This is a review of all climate model cloud feedback mechanisms, including those of high-level clouds and clouds at higher latitudes.

10. Brient F, Schneider T, Tan Z, Bony S, Qu X, Hall A. Shallowness of tropical low clouds as a predictor of climate models' response to warming. Clim Dyn. 2016;47:433-49.

11. Vial J, Bony S, Stevens B, Vogel R. Mechanisms and model diversity of trade-wind shallow cumulus cloud feedbacks: a review. Surv Geophys. 2017;38(6):1331-53. https://doi.org/10.1007/ s10712-017-9418-2. This is a review of our understanding of what controls the spread in low cloud feedbacks from climate models.

12.• Bony S, Stevens B, Frierson DMW, Jakob C, Kageyama M, Pincus R, et al. Clouds, circulation and climate sensitivity. Nat Geosci. 2015;8(4):261-8. https://doi.org/10.1038/ngeo2398. This paper stresses the importance of clouds and their coupling to circulations for understanding climate sensitivity, being one of the WCRP Grand Challenges.

13. Zhou C, Zelinka MD, Klein SA. Analyzing the dependence of global cloud feedback on the spatial pattern of sea surface temperature change with a Green's function approach. J Adv Model Earth Syst. 2017;9:2174-89. https://doi.org/10.1002/2017MS001096.

14. Blossey PN, Bretherton CS, Zhang M, Cheng A, Endo S, Heus T, et al. Marine low cloud sensitivity to an idealized climate change: the CGILS LES intercomparison. J Adv Model Earth Syst. 2013;5(2):234-58. https://doi.org/10.1002/jame.20025.

15. Bretherton CS, Blossey PN, Jones CR. Mechanisms of marine low cloud sensitivity to idealized climate perturbations: a single-LES exploration extending the CGILS cases. J Adv Model Earth Syst. 2013;5(2):316-37. https://doi.org/10.1002/jame.20019.

16. Blossey PN, Bretherton CS, Cheng A, Endo S, Heus T, Lock AP, et al. CGILS phase 2 LES intercomparison of response of subtropical marine low cloud regimes to $\mathrm{CO} 2$ quadrupling and a CMIP3 composite forcing change. J Adv Model Earth Syst. 2016;8(4): 1714-26. https://doi.org/10.1002/2016MS000765. This describes the last CFMIP-GASS Intercomparison of Large Eddy Models (LESs) and their estimates of the cloud feedback in stratocumulus, transition and shallow cumulus cloud regimes.

17. Zhang, M., Bretherton, C. S., Blossey, P. N., Bony, S., Brient, F., and Golaz, J.-C. The CGILS experimental design to investigate low cloud feedbacks in general circulation models by using singlecolumn and large-eddy simulation models, J. Adv. Model. Earth Syst. 2012;4:M12001. https://doi.org/10.1029/2012MS000182.

18. Rieck M, Nuijens L, Stevens B. Marine boundary layer cloud feedbacks in a constant relative humidity atmosphere. J Atmos Sci. 2012;69(8):2538-50. https://doi.org/10.1175/JAS-D-110203.1 .

19. Dal Gesso S, Siebesma AP, de Roode SR, van Wessem JM. A mixed-layer model perspective on stratocumulus steady states in a perturbed climate. Q J R Meteorol Soc. 2014;140:2119-31. https://doi.org/10.1002/qj.2282.

20. Vogel R, Nuijens L, Stevens B. The role of precipitation and spatial organization in the response of trade-wind clouds to 
warming. J Adv Model Earth Syst. 2016;8(2):843-62. https://doi. org/10.1002/2015MS000568. This LES study describes the behavior of larger and aggregating shallow cumulus clouds and their response to warming.

21. Caldwell P, Bretherton CS. Response of a subtropical stratocumulus-capped mixed layer to climate and aerosol changes. J Clim. 2009;22:20-38. https://doi.org/10.1175/ 2008JCLI1967.1.

22. Siebesma AP, Jakob C, Lenderink G, Neggers RAJ, van Meijgaard E, Teixeira J, Calvo J, Chlond A, Grenier H, Jones C, Kohler M, Kitagawa H, Marquet P, Muller F, Olameda D, Severijns C. Cloud representation in GCMs over the Northern Pacific Ocean: A EUROCS intercomparison study. Quart. J Roy Meteor Soc. 2004;130:3245-3268.

23. Bretherton CS, Blossey PN. Low cloud reduction in a greenhousewarmed climate: results from Lagrangian LES of a subtropical marine cloudiness transition. J Adv Model Earth Syst. 2014;6: 91-114. https://doi.org/10.1002/2013MS000250. This study describes the relative importance of large-scale forcing changes under global warming on the transition of stratocumulus to $\mathrm{cu}$ mulus and implications for the low cloud feedback.

24. van der Dussen JJ, de Roode SR, Dal Gesso S, Siebesma AP. An LES model study of the influence of the free tropospheric thermodynamic conditions on the stratocumulus response to a climate perturbation. J Adv Model Earth Syst. 2015;7:670-91. https:// doi.org/10.1002/2014MS000380.

25. Wyant, M. C., Bretherton, C. S., and Blossey, P. N. Subtropical Low Cloud Response to a Warmer Climate in a Superparameterized Climate Model. Part I: Regime Sorting and Physical Mechanisms, J. Adv. Model. Earth Syst.2009;1-7. https://doi.org/10.3894/JAMES.2009.1.7

26. Neggers R, Stevens B, Neelin JD. A simple equilibrium model for shallow-cumulus-topped mixed layers. Theor Comput Fluid Dyn. 2006;20(5-6):305-22. https://doi.org/10.1007/s00162-006-0030-1.

27. Nuijens L, Serikov I, Hirsch L, Lonitz K, Stevens B. The distribution and variability of low-level cloud in the North Atlantic trades. Q J R Meteorol Soc. 2014;140(684):2364-74. https://doi. org/10.1002/qj.2307.

28. Tan Z, Schneider T, Teixeira J, Pressel KG. Large-eddy simulation of subtropical cloud-topped boundary layers: 1 . A forcing framework with closed surface energy balance. J Adv Model Earth Syst. 2016;8:1565-85. https://doi.org/10.1002/2016MS000655.

29. Tan Z, Schneider T, Teixeira J, Pressel KG. Large-eddy simulation of subtropical cloud-topped boundary layers: 2 . Cloud response to climate change. J Adv Model Earth Syst. 2017;9:19-38. https:// doi.org/10.1002/2016MS000804.

30. Qu X, Hall A, Klein S, Caldwell P. On the spread of changes in marine low cloud cover in climate model simulations of the $21 \mathrm{st}$ century. Clim Dyn. 2014;42(9-10):2603-26. https://doi.org/10. 1007/s00382-013-1945-z.

31. Myers TA, Norris JR. Observational evidence that enhanced freetropospheric subsidence reduces marine boundary layer cloudiness. J Clim. 2013;26:7507-24. https://doi.org/10.1175/JCLI-D12-00736.1.

32. Klein SA, Hartmann DL. The seasonal cycle of low stratiform clouds. J Clim. 1993;6:1587-606.

33. Wood R, Bretherton CS. On the relationship between Stratiform low cloud cover and lower-tropospheric stability. J Clim. 2006;19(24):6425-32. https://doi.org/10.1175/JCLI3988.1.

34. Myers TA, Norris JR. On the relationships between subtropical clouds and meteorology in observations and CMIP3 and CMIP5 models. J Clim. 2015;28:2945-67. https://doi.org/10.1175/JCLID-14-00475.1.
35. Eastman R, Wood R. The competing effects of stability and humidity on subtropical stratocumulus entrainment and cloud evolution from a Lagrangian perspective. J Atmos Sci. 2018;75(8): 2563-78. https://doi.org/10.1175/JAS-D-18-0030.1.

36. Christensen MW, Carrio GG, Stephens GL, Cotton WR. Radiative impacts of free-tropospheric clouds on the properties of marine stratocumulus. J Atmos Sci. 2013;70:3102-18. https://doi.org/ 10.1175/JAS-D-12-0287.1.

37. Klein SA. Synoptic variability of low-cloud properties and meteorological parameters in the subtropical trade wind boundary layer. J Clim. 1997;10:2018-39.

38. Norris JR, Iacobellis SF. North Pacific cloud feedbacks inferred from synoptic-scale dynamic and thermodynamic relationships. J Clim. 2005;18(22):4862-78. https://doi.org/10.1175/JCLI3558.1.

39. Zelinka MD, Grise KM, Klein SA, Zhou C, DeAngelis AM, Christensen MW. Drivers of the low-cloud response to poleward jet shifts in the North Pacific in observations and models. J Clim. 2018;31:7925-47. https://doi.org/10.1175/JCLI-D-18-0114.1.

40. Brueck M, Nuijens L, Stevens B. On the seasonal and synoptic time-scale variability of the North Atlantic Trade Wind Region and its low-level clouds. J Atmos Sci. 2014;72(4):1428-46. https://doi.org/10.1175/JAS-D-14-0054.1.

41. Nuijens L, Medeiros B, Sandu I, Ahlgrimm M. Observed and modeled patterns of covariability between low-level cloudiness and the structure of the trade-wind layer. J Adv Model Earth Syst. 2015;7(4):1741-64. https://doi.org/10.1002/ 2015MS000483. This study highlights differences in the behavior of low cloud amount in observations with that in global climate models and discusses implications for modeled cloud feedbacks.

42. Qu X, Stephen AH, Klein A, DeAngelis AM. Positive tropical marine low-cloud cover feedback inferred from cloudcontrolling factors. Geophys Res Lett. 2015;42(18):7767-7775

43. Zhai C, Jiang JH, Su H. Long-term cloud change imprinted in seasonal cloud variation: more evidence of high climate sensitivity. Geophys Res Lett. 2015;42:8729-37. https://doi.org/10.1002/ 2015GL065911.

44. Myers TA, Norris JR. Reducing the uncertainty in subtropical cloud feedback. Geophys Res Lett. 2016;43:2144-8. https://doi. org/10.1002/2015GL067416.

45. Brient F, Schneider T. Constraints on climate sensitivity from space-based measurements of low-cloud reflection. J Clim. 2016;29:5821-34. https://doi.org/10.1175/JCLI-D-15-00897.1.

46. McCoy DT, Eastman R, Hartmann DL, Wood R. The Change in low cloud cover in a warmed climate inferred from AIRS, MODIS, and ERA-Interim. J Clim. 2017;30:3609-20. https:// doi.org/10.1175/JCLI-D-15-0734.1.

47.• Ceppi P, Gregory JM. Relationship of tropospheric stability to climate sensitivity and Earth's observed radiation budget. Proc Natl Acad Sci. 2017;114(50):13126 LP-13131. https://doi.org/ 10.1073/pnas.1714308114. This study highlights how changes in tropospheric stability with warming control (cloud) feedbacks and climate sensitivity.

48.• Andrews T, Webb MJ. The dependence of global cloud and lapse rate feedbacks on the spatial structure of tropical Pacific warming. J Clim. 2017;31(2):641-54. https://doi.org/10.1175/JCLI-D-170087.1. This study highlights the uncertainty in (cloud) feedback estimates related to changing SST patterns with global warming in global climate models.

49. Frenger I, Gruber N, Knutti R, Münnich M. Imprint of Southern Ocean eddies on winds, clouds and rainfall. Nat Geosci. 2013;6: 608-12. https://doi.org/10.1038/ngeo1863.

50. Byrne D, Papritz L, Frenger I, Münnich M, Gruber N. Atmospheric response to mesoscale sea surface temperature anomalies: assessment 
of mechanisms and coupling strength in a high-resolution coupled model over the South Atlantic. J Atmos Sci. 2014;72(5):1872-90. https://doi.org/10.1175/JAS-D-14-0195.1.

51. Bellomo K, Clement A, Mauritsen T, Radel G, Stevens B. Simulating the role of subtropical stratocumulus clouds in driving Pacific climate variability. J Clim. 2014;27:5119-31. https://doi. org/10.1175/JCLI-D-13-00548.1.

52. Bellomo K, Clement A, Mauritsen T, Radel G, Stevens B. The influence of cloud feedbacks on equatorial Atlantic variability. J Clim. 2015;28:2725-44. https://doi.org/10.1175/JCLI-D-14-00495.1.

53. Betts AK, Ridgway W. Climatic equilibrium of the atmospheric convective boundary layer over a tropical ocean. J Atmos Sci. 1989;46:2621-41.

54. Sun D-Z, Liu Z. Dynamic Ocean-atmosphere coupling : a thermostat for the tropics. Science. 1996;272(5265):1148-50.

55. Back LE, Bretherton CS. On the relationship between SST gradients, boundary layer winds, and convergence over the tropical oceans. J Clim. 2009;22(15):4182-96. https://doi.org/10.1175/ 2009JCLI2392.1.

56. Richter I, Behera S, Doi T, Taguchi B, Masumoto Y, Xie S-P. What controls equatorial Atlantic winds in boreal spring? Clim Dyn. 2014;43(11):3091-104. https://doi.org/10.1007/s00382014-2170-0.

57. Muller CJ, Held IM. Detailed investigation of the self-aggregation of convection in cloud-resolving simulations. J Atmos Sci. 2012;69(8):2551-65. https://doi.org/10.1175/JAS-D-11-0257.1.

58. Wing AA, Emanuel KA. Physical mechanisms controlling selfaggregation of convection in idealized numerical modeling simulations. J Adv Model Earth Syst. 2014;6(1):59-74. https://doi.org/ 10.1002/2013MS000269.

59. Hohenegger C, Stevens B. Coupled radiative convective equilibrium simulations with explicit and parameterized convection. $\mathrm{J}$ Adv Model Earth Syst. 2016;8(3):1468-82. https://doi.org/10. 1002/2016MS000666.

60. Mauritsen T, Stevens B. Missing iris effect as a possible cause of muted hydrological change and high climate sensitivity in models. Nat Geosci. 2015;8(5):346-51. https://doi.org/10.1038/ngeo2414.

61. Bretherton CS, Sobel AH. A simple model of a convectively coupled walker circulation using the weak temperature gradient approximation. J Clim. 2002;15(20):2907-20. https://doi.org/10. 1175/1520-0442(2002)015<2907:ASMOAC >2.0.CO;2.

62. Peters ME, Bretherton CS. A simplified model of the Walker circulation with an interactive ocean mixed layer and cloudradiative feedbacks. J Clim. 2005;18(20):4216-34. https://doi. org/10.1175/JCLI3534.1.

63. Nuijens L, Emanuel K. Congestus modes in circulating equilibria of the tropical atmosphere in a two-column model. Q J R Meteorol Soc. 2018;144:28(6)-2692. https://doi.org/10.1002/qj.3385.

64. Emanuel K. Quasi-equilibrium dynamics of the tropical atmosphere. In: Schneider T, Sobel AH, editors. The Global Circulation of the Atmosphere. Princeton: Princeton University Press; 2007. p. 186-218.

65. Naumann AK, Stevens B, Hohenegger C, Mellado JP. A conceptual model of a shallow circulation induced by prescribed lowlevel radiative cooling. J Atmos Sci. 2017;74(10):3129-44. https://doi.org/10.1175/JAS-D-17-0030.1. This conceptual study shows that shallow cloud-topped boundary layers can induce circulations through their radiative effect.

66. Zhang C, Nolan DS, Thorncroft CD, Nguyen H. Shallow meridional circulations in the tropical atmosphere. J Clim. 2008;21(14): 3453-70. https://doi.org/10.1175/2007JCLI1870.1.

67. Lindzen RS, Nigam S. On the role of sea surface temperature gradients in forcing low-level winds and convergence in the tropics. J Atmos Sci. 1987;44:2418-36.
68. Sobel AH, Neelin JD. The boundary layer contribution to intertropical convergence zones in the quasi-equilibrium tropical circulation model framework. Theor Comput Fluid Dyn. 2006;20(56):323-50. https://doi.org/10.1007/s00162-006-0033-y.

69. Nelson EL, L'Ecuyer TS. Global character of latent heat release in oceanic warm Rain Systems. J Geophys Res: Atmos. 2018;123(10):4797-817. https://doi.org/10.1002/2017JD027844.

70. Chen B, Liu C. Warm organized Rain Systems over the tropical eastern Pacific. J Clim. 2015;29(9):3403-22. https://doi.org/10. 1175/JCLI-D-15-0177.1.

71. Blossey, P. N., Bretherton, C. S., and Wyant, M. C. Subtropical Low Cloud Response to a Warmer Climate in a Superparameterized Climate Model. Part II: Column Modeling with a Cloud Resolving Model, J. Adv. Model. Earth Syst. 2009;1-8. https://doi.org/10.3894/JAMES.2009.1.8.

72. Seifert A, Heus T, Pincus R, Stevens B. Large-eddy simulation of the transient and near-equilibrium behavior of precipitating shallow convection. J Adv Model Earth Syst. 2015;7(4):1918-37. https://doi.org/10.1002/2015MS000489. This LES study investigates the response of organized precipitating cumulus clouds to changes in cloud droplet number concentration, and shows that the overall effect of aerosol on the albedo of the cloud field is small..

73. Stevens B, Brogniez H, Kiemle C, Lacour J-L, Crevoisier C, Kiliani J. Structure and dynamical influence of water vapor in the lower tropical troposphere. Surv Geophys. 2017;38:137197. https://doi.org/10.1007/s10712-017-9420-8.

74. Mapes BE, Zuidema P. Radiative-dynamical consequences of dry tongues in the tropical troposphere. J Atmos Sci. 1996;53(4):620 38. https://doi.org/10.1175/1520-0469(1996)053<0620: RDCODT >2.0.CO;2.

75. Pincus R, Beljaars A, Buehler SA, Kirchengast G, Ladstaedter F, Whitaker JS. The representation of tropospheric water vapor over low-latitude oceans in (re-)analysis: errors, impacts, and the ability to exploit current and prospective observations. Surv Geophys. 2017;38(6):1399-423. https://doi.org/10.1007/s10712-017-9437$\mathrm{z}$.

76. Kiemle C, Groß S, Wirth M, Bugliaro L. Airborne Lidar observations of water vapor variability in tropical shallow convective environment. Surv Geophys. 2017;38(6):1425-43. https://doi. org/10.1007/s10712-017-9431-5.

77. Nehrir AR, Kiemle C, Lebsock MD, Kirchengast G, Buehler SA, Löhnert U, et al. Emerging technologies and synergies for airborne and space-based measurements of water vapor profiles. Surv Geophys. 2017;38(6):1445-82. https://doi.org/10.1007/s10712017-9448-9.

78. Nuijens L, Stevens B. The Influence of Wind Speed on Shallow Marine Cumulus Convection. J Atmos Sci 2012;69(1):168-184

79. Di Giuseppe F, Tompkins AM. Generalizing cloud overlap treatment to include the effect of wind shear. J Atmos Sci. 2015;72(8): 2865-76. https://doi.org/10.1175/JAS-D-14-0277.1.

80. Li Z, Zuidema P, Zhu P. Simulated convective invigoration processes at trade wind cumulus cold Pool boundaries. J Atmos Sci. 2014;71(8):2823-41. https://doi.org/10.1175/JAS-D-13-0184.1.

81. Wang S, Zheng X, Jiang Q. Strongly sheared stratocumulus convection: an observationally based large-eddy simulation study. Atmos Chem Phys. 2012;12:5223-35. https://doi.org/10.5194/ acp-12-5223-2012.

82. Mellado JP. Cloud-top entrainment in stratocumulus clouds. Annu Rev Fluid Mech. 2017;49(1):145-69. https://doi.org/10.1146/ annurev-fluid-010816-060231. This is a review of the understanding of entrainment mechanisms at the stratocumulus tops from direct numerical simulations. 
83. Schulz B, Mellado JP. Wind shear effects on radiatively and evaporatively driven stratocumulus tops. J Atmos Sci. 2018;75(9):3245-63. https://doi.org/10.1175/JAS-D-18-0027.1.

84. Agee EM, Chen TS, Dowell KE. A review of mesoscale cellular convection. Bull Am Meteorol Soc. 1973;54:1004-12.

85. Emanuel, K.A., and M.F. Khairoutdinov, 2010: Aggregated convection and the regulation of tropical climate. Preprints, 29th conference on Hurricanesand Tropical Meteorology, Tucson, AZ, Amer. Meteor. Soc., P2.69. Available online at http://ams. confex.com/ams/pdfpapers/168418.pdf. Accessed 15 April 2019.

86. Coppin D, Bony S. Physical mechanisms controlling the initiation of convective self-aggregation in a general circulation model. $\mathrm{J}$ Adv Model Earth Syst. 2015;7(4):2060-78. https://doi.org/10. 1002/2015MS000571.

87. Tobin I, Bony S, Roca R. Observational evidence for relationships between the degree of aggregation of deep convection, water vapor, surface fluxes, and radiation. J Clim. 2012;25:6885-904.

88. Tompkins AM, Semie AG. Organization of tropical convection in low vertical wind shears: role of updraft entrainment. J Adv Model Earth Syst. 2017;9(2):1046-68. https://doi.org/10.1002/ 2016MS000802.

89. Wood RKO, Bretherton CS, Mohrmann J, Albrecht BA, Zuidema P, Ghate V, Schwartz C, Eloranta E, Glienke S, Shaw RA, Fugal J, Minnis P. Ultraclean Layers and Optically Thin Clouds in the Stratocumulus-to-Cumulus Transition. Part I: Observations. J. Atmos. Sci. 2018;75:1631-1652. https://doi.org/10.1175/JAS-D17-0213.1. This studies highlights the presence of thin cloud layers in the subtropical cloud regimes and discusses their formation and implications for cloud radiative effects.

90. Kuan-Ting O, Wood R, Tseng HH. DDeeper, Precipitating PBLs Associated With Optically Thin Veil Clouds in the $\mathrm{Sc}-\mathrm{Cu}$ Transition. Geophys Res Lett. 2018;45(10):5177-5184. https:// doi.org/10.1029/2018GL077084

91. Lenderink G, Holtslag AA. Evaluation of the kinetic energy approach for modeling turbulent Fluxesin stratocumulus. Mon Weather Rev. 2000;128:244-58. https://doi.org/10.1175/15200493(2000)128<0244:EOTKEA >2.0.CO;2.

92. Stevens B, Ackerman AS, Albrecht BA, Brown AR, Chlond A, Cuxart J, et al. Simulations of trade wind cumuli under a strong inversion. J Atmos Sci. 2001;58(14):1870-91. https://doi.org/10. 1175/15200469(2001)058<1870:SOTWCU>2.0.CO;2.

93. Lock AP. Factors influencing cloud area at the capping inversion for shallow cumulus clouds. Q J R Meteorol Soc. 2009;135(641): 941-52. https://doi.org/10.1002/qj.424.

94. Seifert A, Heus T. Large-eddy simulation of organized precipitating trade wind cumulus clouds. Atmos Chem Phys. 2013;13(11): 5631-45. https://doi.org/10.5194/acp-13-5631-2013

95. Li Z, Zuidema P, Zhu P, Morrison H. The sensitivity of simulated shallow cumulus convection and cold pools to microphysics. J Atmos Sci. 2015;72(9):3340-55. https://doi.org/10.1175/JAS-D14-0099.1.

96. Zuidema P, Torri G, Muller C, Chandra A. A survey of precipitation-induced atmospheric cold pools over oceans and their interactions with the larger-scale environment. Surv Geophys. 2017;38(6):L1283-305. https://doi.org/10.1007/ s10712-017-9447-x.

97. Bretherton CS, Blossey PN. Understanding mesoscale aggregation of shallow cumulus convection using large-Eddy simulation. J Adv Model Earth Syst. 2017;9(8):2798-821. https://doi.org/10. $1002 / 2017 \mathrm{MS} 000981$. This study describes the latest insights on what controls mesoscale aggregation of shallow convection in state-of-the-art LES.

98. van Zanten $\mathrm{MC}$, et al. Controls on precipitation and cloudiness in simulations of trade-wind cumulus as observed during RICO. J
Adv Model Earth Syst. 2011;3:M06001. https://doi.org/10.1029/ 2011MS000056.

99. Narenpitak P, Bretherton CS, Khairoutdinov MF. Cloud and circulation feedbacks in a near-global aquaplanet cloud-resolving model. J Adv Model Earth Syst. 2017;9(2):1069-90. https://doi. org/10.1002/2016MS000872.

100. Randall D, DeMott C, Charlotte CS, Khairoutdinov M, Benedict J, McCrary R, et al. Simulations of the tropical general circulation with a multiscale global model. Meteorol Monogr. 2016;57:15.115.15. https://doi.org/10.1175/AMSMONOGRAPHS-D-150016.1.

101. Grabowski WW, Smolarkiewicz PK. CRCP: a cloud re-solving convection parameterization for modeling the tropical convecting atmosphere. Physica D: Nonlinear Phenomena. 1999;55 133:1718. https://doi.org/10.1016/S0167-2789(99)00104-9.

102. Kahn BH, Teixeira J, Fetzer EJ, Gettelman A, Hristova-Veleva SM, Huang X, et al. Temperature and water vapor variance scaling in global models: comparisons to satellite and aircraft data. $\mathrm{J}$ Atmos Sci. 2011;68(9):2156-68. https://doi.org/10.1175/ 2011JAS3737.

103. Parishani H, Pritchard MS, Bretherton CS, Wyant MC, Khairoutdinov M. Toward low-cloud-permitting cloud superparameterization with explicit boundary layer turbulence. J Adv Model Earth Syst. 2017;9:1542-71. https://doi.org/10.1002/ 2017MS000968.

104. Parishani H, Pritchard MS, Bretherton CS, Terai CR, Wyant MC, Khairoutdinov $\mathrm{M}$, et al. Insensitivity of the cloud response to surface warming under radical changes to boundary layer turbulence and cloud microphysics: results from the ultraparameterized CAM. J Adv Model Earth Syst. 2018;10:3139-58. https://doi.org/ 10.1029/2018MS001409.

105. Jansson, F., G. van den Oord, I. Pelupessy, J.H. Grönqvist, A.P. Siebesma and D.T. Crommelin: Regional superparameterization of clouds and turbulence with 3D LES models in OpenIFS submitted to JAMES (2018).

106. Schneider T, Lan S, Stuart A, Teixeira J. Earth system modeling 2.0: a blueprint for models that learn from observations and targeted high-resolution simulations. Geophys Res Lett. 2017;44(12):396-12,417. https://doi.org/10.1002/ 2017GL076101.

107. O'Gorman PA, Dwyer JG. Using machine learning to parameterize moist convection: potential for modeling of climate, climate change, and extreme events. J Adv Model Earth Syst. 2018;10: 2548-63. https://doi.org/10.1029/2018MS001351.

108. McGibbon J, Bretherton CS. Skill of ship-following large-eddy simulations in reproducing MAGIC observations across the Northeast Pacific stratocumulus to cumulus transition region. J Adv Model Earth Syst. 2017;9(2):L810-31. https://doi.org/10. 1002/2017MS000924

109. Schalkwijk J, Jonker HJJ, Siebesma AP, Bosveld FC. A year-long large-Eddy simulation of the weather over Cabauw: an overview. Mon Weather Rev. 2014;143(3):828-44. https://doi.org/10.1175/ MWR-D-14-00293.1.

110. Heinze R, Moseley C, Böske L, Muppa SK, Maurer V, Raasch S, et al. Evaluation of large eddy simulations forced with mesoscale model output for a multi-week period during a measurement campaign. Atmos Chem Phys. 2017;17:7083-109. https://doi.org/10. 5194/acp-17-7083-2017.

111. Satoh M, Tomita H, Yashiro H, Kajikawa Y, Miyamoto Y, Yamaura T, et al. Outcomes and challenges of global highresolution non-hydrostatic atmospheric simulations using the $\mathrm{K}$ computer. Prog Earth Planet Sci. 2017;4(1):13. https://doi.org/ 10.1186/s40645-017-0127-8. 
112. Bony S, Stevens B, Ament F, Bigorre S, Chazette P, Crewell S, et al. EUREC4A: a field campaign to elucidate the couplings between Clouds, Convection and Circulation. Surv Geophys. 2017;38(6):1529-68. https://doi.org/10.1007/s10712-017-9428-0.

113. Mellado JP, Bretherton CS, Stevens B, Wyant MC. DNS and LES for simulating stratocumulus: better together. J Adv Model Earth Syst. 2018;10:1421-38. https://doi.org/10.1029/2018MS001312.

114. Jakob C, Lenderink G, Neggers RAJ, van Meijgaard E, Teixeira J, Calvo J, et al. Cloud representation in GCMs over the Northern Pacific Ocean: a EUROCS intercomparison study. Q J R Meteorol Soc. 2004;130:3245-68.
115. Kuan-Ting O, Wood R, Tseng HH. Deeper, precipitating PBLs associated with optically thin veil clouds in the $\mathrm{Sc}-\mathrm{Cu}$ transition. Geophys Res Lett. 2018;45(10):5177-84. https://doi.org/10.1029/ 2018 GL077084.

116. W. Grabowski. Towards global large Eddy simulation: superparameterization revisited. J Meteorol Soc Jpn Ser. II. 2017;94(4):327-44.

Publisher's Note Springer Nature remains neutral with regard to jurisdictional claims in published maps and institutional affiliations. 